\title{
Functioning devices for solar to fuel conversion
}

\author{
Guido Mul $^{\mathrm{a}, *}{ }$, Christian Schacht ${ }^{\mathrm{b}}$, Wim P.M. van Swaaij ${ }^{\mathrm{c}}$, Jacob. A. Moulijn ${ }^{\mathrm{d}}$ \\ a PCS Group, Faculty of Science and Technology, University of Twente, P.O. Box 217, 7500 AE Enschede, The Netherlands \\ b Process and Engineering Laboratory, Delft University of Technology, Julianalaan 136, 2628 BL Delft, The Netherlands \\ ${ }^{\text {c }}$ TCCB Group, Faculty of Science and Technology, University of Twente, P.O. Box 217, 7500 AE Enschede, The Netherlands \\ d Catalysis Engineering Group, DelftChemTech, Delft University of Technology, Julianalaan 136, 2628 BL Delft, The Netherlands
}

\section{A R T I C L E I N F O}

\section{Article history:}

Received 8 February 2011

Received in revised form 31 May 2011

Accepted 3 June 2011

Available online 3 August 2011

\section{Keywords:}

Solar

Fuel

Electrocatalysis

Photocatalysis

Thermal

Photosynthesis

Artificial

Perspective

\begin{abstract}
A B S T R A C T
This paper provides a perspective on the technologies capable of converting solar energy, $\mathrm{CO}_{2}$ and $\mathrm{H}_{2} \mathrm{O}$ into an easy to use fuel. The paper addresses bio-based approaches, but mainly focuses on (i) the combination of photovoltaic (PV) devices and electrocatalysis, (ii) single unit operation by photocatalytic conversion, and (iii) solar thermal conversion. Each option is described in a general manner, including a brief evaluation of the advantages and disadvantages. Also suggestions for future research endeavours are given. Based on the used literature data, for electrocatalytic and photocatalytic technologies, dramatic improvements should be made in material optimization, as well as reactor design and operation. Large efficiency gains are necessary to enable use of these technologies in practice. Solar thermal conversion is more mature, and requires specific optimization in processing, as will be discussed.
\end{abstract}

(C) 2011 Elsevier B.V. All rights reserved.

\section{Introduction}

In photosynthesis, nature harvests solar energy and stores it in what is generally referred to as biomass. The basic reaction (reaction (1)) is the reduction of $\mathrm{CO}_{2}$ with water, giving glucose and oxygen [1]:

$$
\mathrm{CO}_{2}+\mathrm{H}_{2} \mathrm{O} \rightarrow 1 / 6 \mathrm{C}_{6} \mathrm{H}_{12} \mathrm{O}_{6}+\mathrm{O}_{2} \quad \Delta G=522 \mathrm{~kJ} / \mathrm{mol}
$$

Glucose builds the basis for 'biomass', consisting mainly of cellulose, a polymer of glucose, hemicellulose and lignin. Over the ages, in complex networks of sequential reactions, fossil fuels such as oil, coal and natural gas are formed from biomass, in which gigantic amounts of energy are stored, see Table 1 [2-4].

At present, mankind benefits from the energy stored in fossil fuels but the well-known dilemma is the following. The data presented in Table 1 show that we are relatively quickly consuming fossil fuels. This 'easy' energy will not last forever and on top of this, the side effects of polluting the environment are evident.

Although the numbers in Table 1 are spectacular and perhaps alarming, one number leads to optimism: there is plenty of solar energy flowing continuously to the surface of the earth. Even in

\footnotetext{
* Corresponding author.

E-mail address: G.Mul@utwente.nl (G. Mul).
}

photosynthesis only a tiny fraction of the total available solar energy is used. So, why not use sunlight directly instead of burning or converting fossil fuels that have been formed in a time period of billions of years? In principle sunlight is not associated with undesired side effects such as global warming and other types of pollution.

It is also important to realize that besides energy, mankind depends on food, materials, and other chemical products. At present, fossil fuels are the main basis for both energy and chemicals. Also in this respect solar energy can replace fossil fuels, at least partly. Solar energy, if it becomes sufficiently cheap, can unlock many potential sources of materials and chemicals.

\section{Current and potential processes}

Several options for solar energy harvesting and converting this to chemical energy have been proposed and are topics of intensive research $[1,5]$. These can be divided in the following themes:

- Increasing the extent of bio-based, 'normal', photosynthesis. The surface of land available for agriculture can be expanded. Another strategy is to increase the efficiency of agriculture in terms of higher output per $\mathrm{m}^{2}$. Constraints are the limited amount of surface of land available, inefficiency of biological processes, waste that is produced, as well as limitations on supply of water and 
Table 1

Key figures in photosynthesis (worldwide) [2-4].

\begin{tabular}{lll}
\hline & $\begin{array}{l}\text { Energy } \\
\text { flow (TW) }\end{array}$ & $\begin{array}{l}\text { Reserves/production } \\
\text { (year) }\end{array}$ \\
\hline Radiation reaching earth & $125.000^{\mathrm{a}}$ & \\
Natural photosynthesis & 130 & \\
Present energy consumption & $13.9^{\mathrm{b}}$ & \\
Energy consumption expected for 2050 & $49^{\mathrm{c}}$ & \\
Biomass (for energy) & $1.5^{\mathrm{d}}$ & \\
Coal & 4.4 & 190 \\
Oil & 5.2 & 42 \\
Natural gas & 3.6 & 63 \\
\hline
\end{tabular}

a Depending on time of day and location.

b 2005.

c 3.5 times 2005 number.

d 2007, mainly cooking/heating.

minerals (including $\mathrm{P}$ and $\mathrm{N}$ in suitable form). An alternative to exploiting land is to develop biological processes in water (lakes/seas), e.g., producing algae [6]. Certainly harvesting, and removing the large excess of water are challenges to be dealt with [7-9].

- Applying alternative technologies for direct harvesting of solar energy, without the use of living cells. This is a wide field with many options. Along the energy chain of photons, electrons, and energy rich molecules, many possibilities for utilization of solar energy are considered at present. A classical technology that can be expanded is direct heating (solar panels for passive use of sunlight) [1]. Related ideas are to use the IR part of the solar spectrum to provide for the energy needed for endothermic reactions [10]. Alternative technologies are inviting because it might be possible to develop processes more efficient than nature. For the latter a limited efficiency of a few \% (amount of photons used/ amount of photons radiated to a surface) holds [1].

- Apart from passive use of sunlight, state-of-the-art trapping of photons is achieved by using photo-voltaics (solar panels giving direct electricity). Innovations in this technology have resulted already in energy efficiencies that are an order of magnitude higher than nature provides. However, a fundamental aspect of all energy scenarios is energy storage. Plants store energy by producing cellulose (biomass). How can alternative processes store the collected energy? Solar panels for heating and production of electricity as such do not store energy, although batteries and chemical flow batteries are available and being improved. Two other major routes suggest themselves, for storing the collected photonic energy in the form of chemicals:

- $\mathrm{H}_{2}$ production by water splitting [11-16]

- $\mathrm{CO}_{2}$ reduction, combined with water oxidation ( $\mathrm{to}_{2}$ ), yielding liquids such as alcohols or even hydrocarbons. This process is commonly referred to as artificial photosynthesis [17-23].

These processes are extremely attractive because (i) the synthesis reactions are thermodynamically uphill and the energy densities $\left(\mathrm{kg}^{-1}\right)$ very high, and (ii) in 'freeing' the stored energy no problematic emissions are produced.

Whether hydrogen production or $\mathrm{CO}_{2}$ reduction is the better solar to chemical energy conversion route, is currently still under debate, but appears to be a matter of scale. Various research programs target the production of hydrogen by the overall water splitting reaction, in particular for local storage and use of solar energy [24]. The disadvantage of using hydrogen in a larger infrastructure is that it is difficult to store and transport without significant losses [1]. One could state, however, that hydrogensynthesis is an important step of the integrated conversion of $\mathrm{CO}_{2}$ and $\mathrm{H}_{2} \mathrm{O}$. The main arguments for applying the combined reaction of $\mathrm{CO}_{2}$ and $\mathrm{H}_{2} \mathrm{O}$ (artificial photosynthesis) or water splitting $[6,18,25]$ can be summarized as follows. Global hydrocarbon synthesis from $\mathrm{CO}_{2}$ and water is a more effective way to store solar energy than the synthesis of hydrogen (the energy density per volume of a hydrocarbon is much greater than that of hydrogen). Furthermore, hydrocarbons are directly applicable in the current infrastructure for distribution of transport fuels. Ensuring continuity in the use of hydrocarbons for existing synthesis technologies in the chemical industry, as stated previously, is also an absolute necessity. Scientific challenges in the domain of storing solar energy by $\mathrm{CO}_{2}$ conversion are larger than for hydrogen synthesis. $\mathrm{CO}_{2} \mathrm{Con}-$ version in the presence of water can lead to different products, such as methane or methanol, and little is known about the role of the chemical composition and surface structure of electrocatalytic and photo-catalytic converters in triggering selectivity [19-21,26-29]. In the following case studies we will further address the options for chemical storage of solar energy. The authors would like to stress that this paper has not been written with the objective of giving a state of the art review of the various options, but rather to provide a perspective on future technologies.

\subsection{Photovoltaics and its use in fuel production and chemicals/materials}

\subsubsection{Introduction}

Electricity as an energy carrier is extremely versatile because it can be easily transported via a well established infrastructure and it could, at least in principle, be applied for nearly any application requiring energy (exceptions are, e.g., food and feed). Some have argued [1] that in an "All Electric Society", primary energy carriers, including all solar derived sources, should first be converted to electricity, which could, subsequently, be applied to satisfy the whole spectrum of human energy needs (food production, heat, materials, transport, etc.) without requiring any gaseous, liquid or solid fuels. If the primary sources are only based on recent solar radiation energy (and nuclear energy) the whole energy chain can, thus, be detached from the global carbon cycle, oxygen cycle, nitrogen and phosphorus cycle, etc.

It is, however, unlikely that an "All Electric Society" can be realized, at least not on a short or medium time scale (tens of years). Important obstacles are the challenges involved in large scale storage of electricity, be it centralized or decentralized, needed for security of uninterrupted supply. This specially holds in cases where electricity originates from fluctuating sources (wind, photovoltaic, tidal, waves, etc.). Also long distance $(2000-5000 \mathrm{~km})$ transport, in its present form is not yet very efficient with $6-21 \%$ losses compared to oil transport (>1\% loss [30]). Moreover, in offgrid energy applications like cars (in long distance transportation), trucks, tractors, ships, airplanes, etc. fuels are still preferred as long as batteries have a relative low storage capacity per unit weight compared to liquid and gaseous fuels (see Table 3). This does not hold for transport in urban areas where electric trains, subways, trams, hybrids and electric cars, scooters, etc. will probably play an increasingly important role in the future [1].

\subsubsection{Electricity production}

The main production of electrical power takes place in large centralized units and is based on combustion of fossil fuels (a finite resource) with important environmental consequences like $\mathrm{CO}_{2}$, $\mathrm{NO}_{x}$ and particulate emissions [31]. Especially $\mathrm{CO}_{2}$ emissions are in focus nowadays, because of their expected contribution to climate change. However, in the longer term also the security of supply of fossil fuels, like mineral oil, and natural gas and their potential depletion, are important points of concern [31]. Electricity can also be generated from nuclear fission plants but radioactive waste and safety are still main points of discussion in the future expansion of nuclear energy [32,33]. Fusion energy could contribute to electricity generation in a distant future but this remains uncertain 


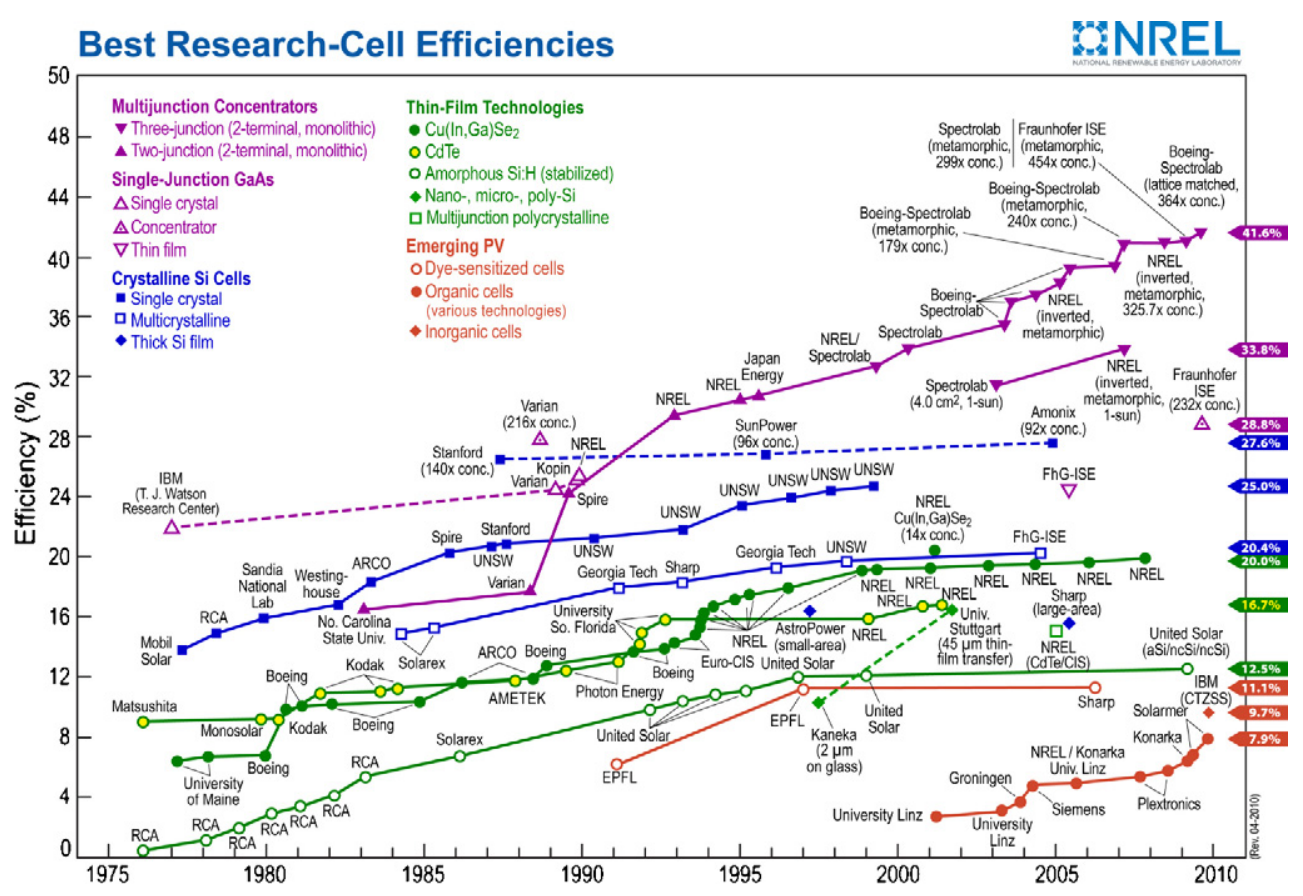

Fig. 1. Best research cell efficiencies, as a function of time [35].

in view of the large steps still to be made [34]. With the exception of tidal energy and geothermal energy, which have a limited contribution at the moment, all other non fossil and non-nuclear sources of electrical energy are based directly or indirectly on solar radiation, and these renewable sources are considered to be most promising for mankind. The total solar radiation received by the earth (see Table 1 ) is more than 10.000 times the human energy consumption. Solar radiation can be harnessed for human needs for heat, food/feed, fuels (e.g., via biomass) and power, but we will focus here on power via electricity generation. Virtually all technologies under investigation, such as photovoltaics, wind, waves, hydropower, temperature differences in seawater, focused solar radiation producing heat, etc. (except hydropower) have the problems of a fluctuating input requiring some form of storage. We will limit our discussion here to photovoltaic conversion of solar radiation in incident or concentrated/ focused form.

\subsubsection{Solar cells}

Photovoltaic conversion of light into electricity is known since its discovery by Becquerel in 1839 but received an important impulse from the rise of semiconductor devices and the early applications in space exploration where it was used as a source of on-board power. Over the years the different types of solar cells were considerably improved leading to impressive research cell efficiencies (see Fig. 1).

In practice the current efficiencies of commercial modules are always lower (see Table 2), because economical optimization will not necessarily lead to the highest efficiency possible. Current developments cover a broad range of cell types based on

Table 2

Efficiencies of laboratory cells and commercial panels.

\begin{tabular}{lll}
\hline Efficiencies & Laboratory cells & Commercial panels \\
\hline Crystalline silicon & Up to $25 \%$ & $12-20 \%$ \\
Thin film silicon & Up to $12 \%$ & $6-8 \%$ \\
CIGS & Up to $20 \%$ & $10-12 \%$ \\
Cd Te & Up to $17 \%$ & $9-11 \%$ \\
Polymer cells & Up to $8 \%$ & $2-4 \%$ (only test panels) \\
\hline
\end{tabular}

crystalline silicon, multi crystalline silicon, ribbon silicon while thin film cells are developed based on a variety of materials like Indium Gallium Di-Selenide. Moreover, junction cells, light absorbing dye cells [36,37] and organic/polymer cells (multiple and silicon thin films) [38,39] are developed, involving nanotechnology (Fig. 2).

Due to the huge potential and rapid developments, the future for photo-voltaics looks bright. At present the cost of electricity compared to other electric power generations is not yet favorable in many cases. It varies strongly with the application and area (latitude, state of development of different countries etc.) but generally for large scale production it is still 2-5 times more expensive than fossil based electricity generation. However, the module price versus experience curve (see Fig. 3) shows a favorable learning behavior and in most future projections it is assumed that photovoltaics in combination with the use of solar heat will play an important role in providing electricity (10-50\%) and possibly in providing fuels. Therefore, on the very long term it could even meet the bulk of the global energy demand.

\subsubsection{Storage}

As for most of the renewable sources, photovoltaic energy is characterized by an intermittent and uncontrollable production rate; night and day rhythm, seasons, weather, and others.

If connected to the grid, to a certain extent this can be accommodated by controlled sources in the generally occurring differences in supply and demand of an extended grid. However, generally some form of electric energy storage will be required if a larger fraction of fluctuating sources has to be accommodated. Storage of large amounts of electrical energy is difficult and costly. Table 3 gives a simplified overview of current and emerging methods. Large scale storage via pumped hydroelectric and compressed air energy storage cycles are already in use for power stations as well as batteries in some location. Some short cycle time devices among others for current quality control like fly wheel, super capacitors and superconducting (magnetic) energy storage are under development. On the longer term hydrogen production and storage cycles will probably grow in importance [24,40]. Only (rechargeable) batteries are suited for off-grid applications together with hydrogen and fuel produced via electrochemical processes. On the long term, battery 


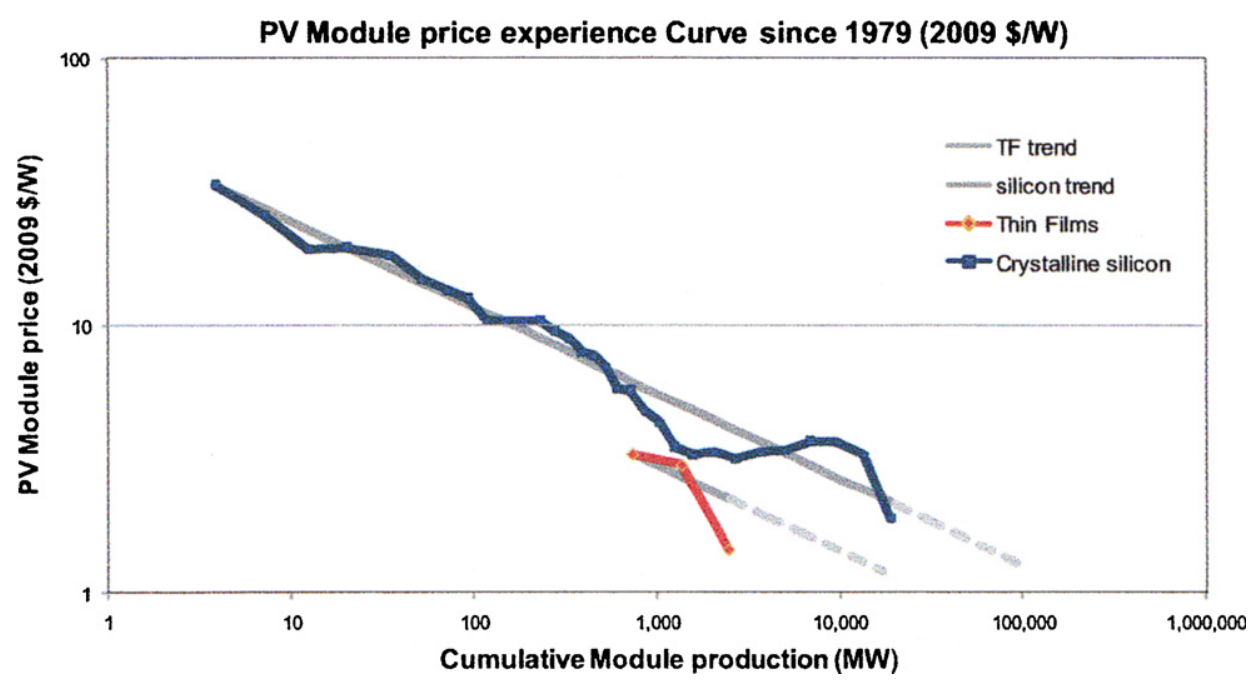

Fig. 2. Price vs. production curve of solar cells [35].

systems may be considerably improved and they will certainly be applied more than today for driving electrical cars for local urban transport. As stated earlier, for other applications like air transport, trucks, long distance transport with cars, tractors, for use in areas devoid of electrical grids, this is less likely. High energy density fluids like hydrocarbons, alcohols and possibly hydrogen will remain attractive (Table 4).

If fossil fuels have to be replaced by fuels based on recycled $\mathrm{CO}_{2}$, photovoltaics may generate the energy necessary to produce these fuels provided the electricity generated is cheap enough. Also many bulk and fine chemicals could be produced via these routes. Fig. 3 gives an overview.

From a photovoltaic power station (if necessary connected to its own local energy storage system and/or to the main grids) the (fluctuating or smoothed) electrical energy could be used for water electrolysis producing hydrogen $[24,40]$. Hydrogen could be combined with $\mathrm{CO}_{2}$ from any source (even recovered from the atmosphere) to produce synthesis gas via the "reversed shift" reaction. Existing processes can be used to produce Fischer-Tropsch hydrocarbon fuels as well as alcohols or other energy rich chemicals.

Atmospheric $\mathrm{CO}_{2}$ is extremely diluted, and apart from other available sources, it could be produced from (waste) biomass via oxy-combustion to produce concentrated $\mathrm{CO}_{2}$. This concentrated $\mathrm{CO}_{2}$ can be used in the reversed shift reaction, which was discussed earlier. The electricity produced in the oxygen combustion can be returned to the power station.

Another route could be to use the oxygen from the electrolysis to produce high quality syngas directly from biomass via oxygen gasification. The $\mathrm{CO}_{2}$ from the biomass oxy-combustion (or from any other source) could alternatively be used in a combined electrolysis process to produce syngas. There could be many other

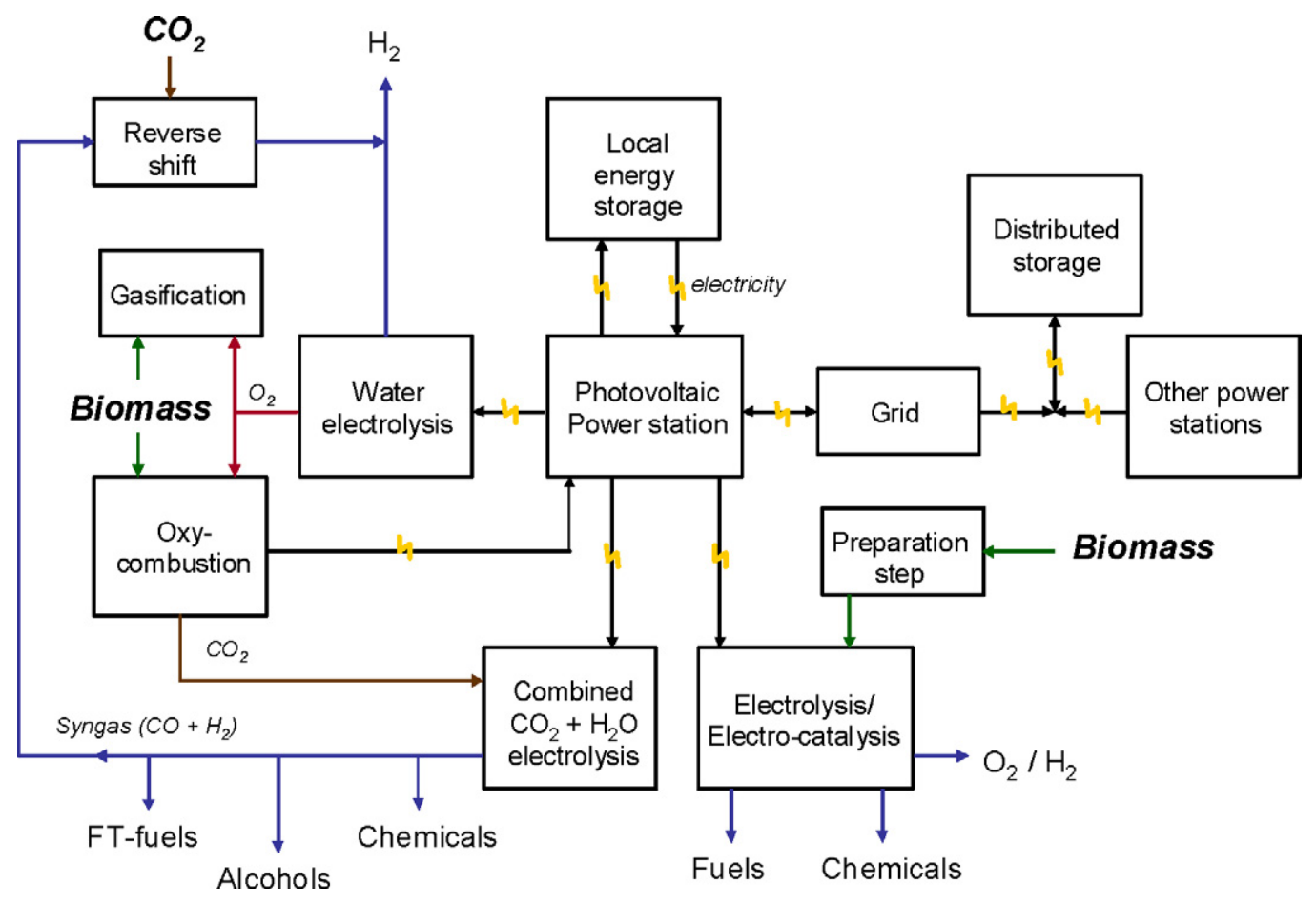

Fig. 3. Options for integrated process operation combining biomass conversion and electrocatalytic steps. 
Table 3

Electric energy storage.

\begin{tabular}{|c|c|}
\hline Electric energy storage & Remarks \\
\hline Pumped hydro electric & In use at suitable location. Large scale \\
\hline Compressed air energy storage & $\begin{array}{l}\text { Some use in suitable locations } \\
\text { Large scale. Related to use of turbine }\end{array}$ \\
\hline Fly wheel energy storage & Short time frame, quality control \\
\hline Super capacitors & Short time frame, quality control \\
\hline $\begin{array}{l}\text { Superconducting energy storage } \\
\text { Superconducting magnetic } \\
\text { energy storage }\end{array}$ & Short time frame. Under development \\
\hline $\begin{array}{l}\text { Batteries: lead acid, sodium sulfur, } \\
\text { vanadium redox flow batteries, } \\
\text { NM Hydride, etc. }\end{array}$ & $\begin{array}{l}\text { Can be used on different scales and for } \\
\text { off-grid application }\end{array}$ \\
\hline $\begin{array}{l}\text { Hydrogen via electrolysis, storage } \\
\text { of hydrogen and power } \\
\text { generation, e.g., via fuel cells }\end{array}$ & $\begin{array}{l}\text { Applicable on different scales and for } \\
\text { off-grid applications (emerging) }\end{array}$ \\
\hline $\begin{array}{l}\text { Introduction of other elements like } \\
\text { carbon (next to hydrogen) to } \\
\text { produce alcohols and } \\
\text { hydrocarbons }\end{array}$ & $\begin{array}{l}\text { Not yet developed. Off-grid } \\
\text { applications, e.g., transport sector }\end{array}$ \\
\hline
\end{tabular}

Table 4

Energy densities for transport [1, and references therein].

\begin{tabular}{lcc}
\hline & MJ/l & MJ/kg \\
\hline Gasoline & 32 & 43 \\
Methanol & 17 & 21 \\
Ethanol & 22 & 28 \\
Hydrogen gas & 0.013 & 120 \\
Hydrogen liquid without container & 8.4 & 120 \\
Hydrogen 350 bar without container & 2.8 & 120 \\
Hydride & 13 & 6 \\
Lead batteries & 0.24 & 0.12 \\
Li-ion batteries & 1.2 & 0.84 \\
\hline
\end{tabular}

routes to introduce the recycled carbon of biomass (after preconversion) into the energy systems to produce fuels and chemicals using electrical energy from photovoltaics without previous partial or total oxidation of the carbon. Electrolysis and electrocatalytic processes or plasma processes could be developed to this end. Once photovoltaic energy becomes economically attractive, fuels and chemicals could be based on recycled carbon avoiding further increase of atmospheric $\mathrm{CO}_{2}$ levels. Additionally many of the chemicals and materials now derived from fossil sources could be produced via these routes, if electricity based processes can be developed. The following paragraph will further focus on the $\mathrm{CO}_{2}$ to fuel conversion by electrocatalysis.

\section{2. $\mathrm{CO}_{2}$ to fuels by electrocatalysis}

\subsubsection{Introduction}

The conversion of $\mathrm{CO}_{2}$ based on solar energy is a challenging topic. An excellent review is given by Centi and Perathoner [18]. On the one hand $\mathrm{CO}_{2}$ could be reduced by $\mathrm{H}_{2}$, which in turn is produced by photocatalytic dissociation of water or by a combination of PV and electrocatalytic dissociation of water (see Fig. 3). An obvious product could be methanol. On the other hand direct photocatalytic or electrochemical reduction of $\mathrm{CO}_{2}$ could be more attractive in the long run.

The combination of PV and electrocatalysis has several advantages as compared to direct photocatalytic conversion. In a photocatalytic reduction, similar to photosynthesis in nature, reduction reactions take place in combination with oxidation reactions leading to $\mathrm{O}_{2}$ formation. The same applies to artifical photocatalysis and eletrocatalytic reduction. However, there is a crucial difference between photocatalysis and electrocatalysis. In the latter, the oxidation and reduction reactions are spatially separated, viz. reduction at the cathode and oxidation at the anode. In the former case this is not trivial, and oxidation reactions can interfere with reduction reactions. In addition, in electrocatalysis, pure $\mathrm{O}_{2}$ is a product that can give added value to the process. The disadvantage is that electrocatalytic conversion is operated in liquid phase conditions, with restrictions in quantities of dissolved $\mathrm{CO}_{2}$, while gas phase electrocatalysis, using solid electrolytes, is not well developed [41].

The reaction mechanism is very complex, and selectivity issues are apparent. Electrocatalysis is associated with an additional handle for influencing selectivity by controlling the electrode potential. The analogue in photocatalysis could be the frequency of the light, which can also be controlled. However, this has not a large potential. Intrinsically the energy levels of the excited state are determined by the so-called band energy levels, i.e., the 'electric potential' is independent on the frequency of light.

For water splitting the situation is different. The spatial argumentation holds also here, but there is no selectivity issue.

A large literature base exist reporting results of electrocatalytic $\mathrm{CO}_{2}$ reduction. However, the results are not yet suggesting the implementation into a full process cycle, because:

- For every novel process development the most important objective is to produce the right product(s). However, the product distributions for electrocatalytic $\mathrm{CO}_{2}$ reduction are not satisfactory. If fuels and high value chemicals are the desired products, usually, the selectivity is limited: major amounts of $\mathrm{H}_{2}$ and $\mathrm{CO}$ are formed, reducing the Faradaic efficiency for the desired products. The chemistry of $\mathrm{CO}_{2}$ conversions is fascinating but the complexity, at present, frustrates practical applications.

- Rates observed are far too low in the processes for production of the desired products.

- Electrodes are not stable and catalyst deactivation is a major issue.

\subsubsection{Reaction pathways}

In aqueous solvents several studies have been reported for the production of $\mathrm{CO}$, Oxalic acid, $\mathrm{CH}_{3} \mathrm{OH}, \mathrm{CH}_{4}$ and other hydrocarbons, a.o. Fischer-Tropsch type of distributions. While hydrocarbons are preferred, in principle a mixture of $\mathrm{CO}$ and $\mathrm{H}_{2}$ would also be desirable, which can be converted through well known catalytic processes in desired products (Fig. 3). Thermodynamics gives a useful basis for an interpretation [18]:

\begin{tabular}{lcc}
\hline Reaction & $E_{0}(\mathrm{~V})$ & $\Delta G(\mathrm{~kJ} / \mathrm{mol})$ \\
\hline $2 \mathrm{H}^{+}+2 \mathrm{e}^{-} \leftrightarrow \mathrm{H}_{2}$ & 0 & 0 \\
$\mathrm{CO}_{2}+2 \mathrm{H}^{+}+2 \mathrm{e}^{-} \leftrightarrow \mathrm{CO}+\mathrm{H}_{2} \mathrm{O}$ & -0.103 & 20 \\
$\mathrm{CO}_{2}+\mathrm{H}^{+}+2 \mathrm{e}^{-} \leftrightarrow \mathrm{vHCOO}^{-}$ & -0.225 & 43 \\
$2 \mathrm{CO}_{2}+12 \mathrm{H}^{+}+12 \mathrm{e}^{-} \leftrightarrow \mathrm{C}_{2} \mathrm{H}_{4}+4 \mathrm{H}_{2} \mathrm{O}$ & 0.079 & -92 \\
$\mathrm{CO}_{2}+8 \mathrm{H}^{+}+8 \mathrm{e}^{-} \leftrightarrow \mathrm{CH}_{4}+2 \mathrm{H}_{2} \mathrm{O}$ & 0.169 & -131 \\
$\mathrm{CO}_{2}+6 \mathrm{H}^{+}+6 \mathrm{e}^{-} \leftrightarrow \mathrm{CH}_{3} \mathrm{OH}+\mathrm{H}_{2} \mathrm{O}$ & 0.03 & \\
\hline
\end{tabular}

In view of this data it is not surprising that $\mathrm{H}_{2}$ formation is a competing reaction. A first requirement for a satisfactory process will be to avoid extensive $\mathrm{H}^{+}$reduction, which clearly will also be influenced by the $\mathrm{pH}$ at which the reaction is conducted [42]. The data suggests that high selectivity to hydrocarbons is achievable, provided that the electrode potential is not too low. However, this is not observed in practice: apparently kinetics is not forgiving.

Thus, for a good evaluation, the elementary steps and their kinetics need to be understood. The key reactions take place at the cathode:

$\mathrm{CO}_{2}+\mathrm{e}^{-} \rightarrow \mathrm{CO}_{2}^{-}$ads

$\mathrm{H}^{+}+\mathrm{e}^{-} \rightarrow \mathrm{H}_{\mathrm{ads}}$

The first reduction step for $\mathrm{CO}_{2}$ is the addition of an electron to an anti-bonding orbital, involving a geometric change of the 


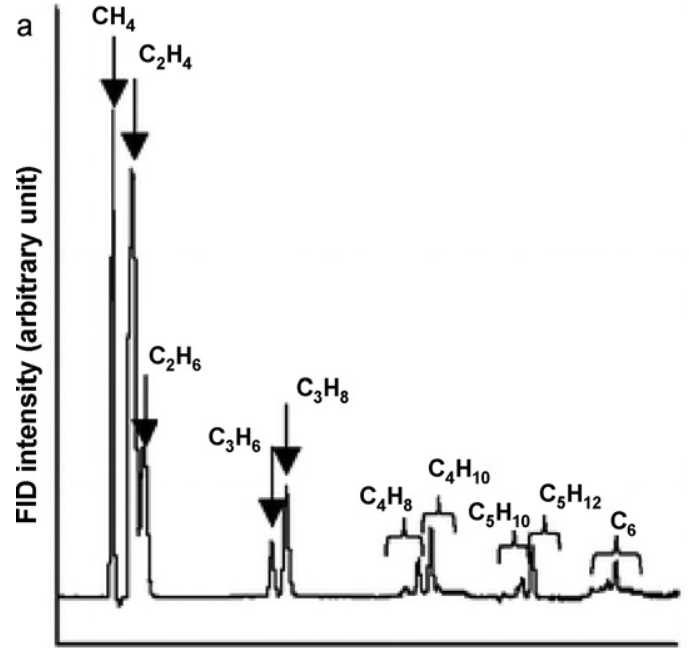

Retention time (arbitrary unit)

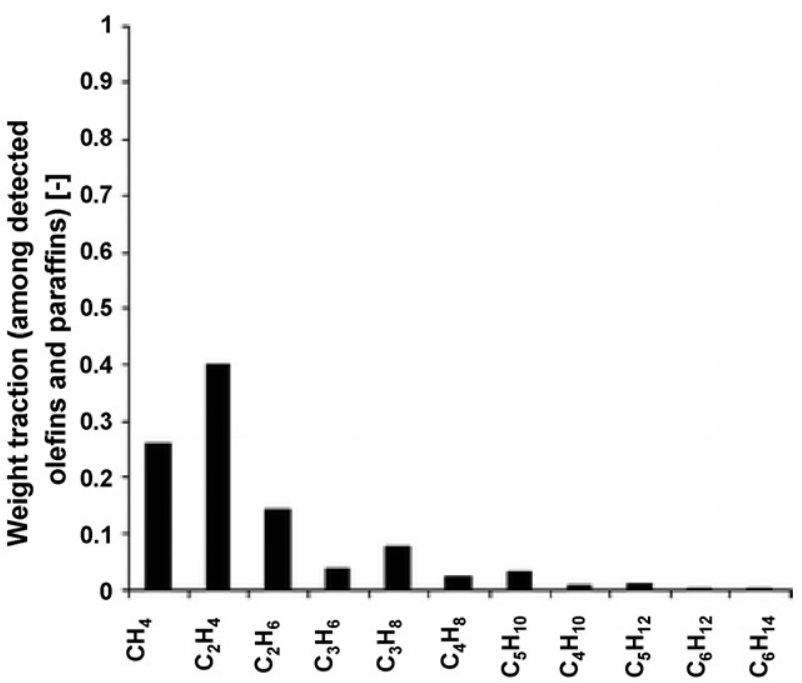

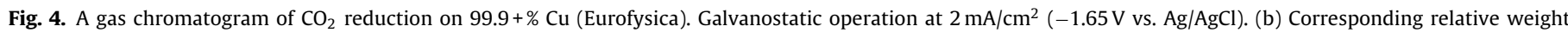
fractions of each of the products formed [19].

molecule. A low reaction rate is expected. The second step will occur in protic media over many metal electrodes. Dependent on the adsorption characteristics, $\mathrm{H}_{2}$ will be formed via:

$2 \mathrm{H}_{\mathrm{ads}} \rightarrow \mathrm{H}_{2}$

Catalysts, which are usually applied for water splitting, should not be selected, or the conditions should be chosen such that this reaction is inhibited. Often, $\mathrm{CO}$ formation is an important side reaction and at high pressures the relatively high $\mathrm{CO}$ occupancy might be high enough to strongly inhibit $\mathrm{H}_{2}$ production.

Sequential reactions take place at the surface:

$$
\begin{aligned}
& \mathrm{CO}_{2}{ }^{-} \text {ads }+\mathrm{H}_{\mathrm{ads}} \rightarrow \mathrm{COOH}_{\mathrm{ad}}, \mathrm{CO}_{\mathrm{ad}} \\
& \rightarrow \rightarrow \text { alcohols, aldehydes, olefins, parafins }
\end{aligned}
$$

It is not surprising that the literature shows a large variety of results. The first reaction steps to build formate and $\mathrm{CO}$ are rather well understood. The remainder of the network of reduction steps have recently been discussed in detail [43].

Because of the low solubility of $\mathrm{CO}_{2}$ in aqueous media, other organic solvents have been used, including methanol [44]. In general, within aqueous and protic solvents, $\mathrm{H}_{2}$ production takes place extensively, reducing the Faradaic efficiency of the process. In aprotic solvents this is obviously not the case. However, for the formation of fuels, protons are needed and in aprotic solvents $\mathrm{CO}$ and oxalates are the main products [45]. Moreover, currently reported densities are low. Also Ionic Liquids have recently been tried-with limited success. $\mathrm{CO}_{2}$ undergoes a chemically irreversible, one-electron electrochemical reduction [46]. Therefore, aqueous systems are preferred and the low solubility in aqueous systems has to be overcome by other means, such as a high pressure.

For fuel synthesis $\mathrm{Cu}$ appears the preferred electrode material. The product mixture typically consists of $\mathrm{CO}, \mathrm{CH}_{4}, \mathrm{C}_{2} \mathrm{H}_{4}, \mathrm{C}_{2} \mathrm{H}_{5} \mathrm{OH}$ and $\mathrm{HCOOH}$. A breakthrough might be the discovery that higher hydrocarbons are formed under certain conditions [21,47]. Recent results even show that for specific $\mathrm{Cu}$ electrodes Fischer-Tropsch distributions are encountered, see Fig. 4 [19]. The Faradaic efficiency is low, mainly because of the competing dissociation of water.

Although this technology is far from practically applicable, at least it can be considered promising. This process belongs to the gas-to-liquid technology and is completely based on both sustainable energy and reactants [25].

\subsubsection{Practical process, is it realistic?}

In development of an electrocatalytic process usually crucial parameters are selectivity, including Faradaic efficiency, activity and stability. For the present process this is also the case.

In general, rather low current densities $\left(2-5 \mathrm{~mA} / \mathrm{cm}^{2}\right)$ are reported. This translates to the value given in Fig. 5, for which the activity data reported in Fig. 4 were used. Clearly, for an efficient process these values have to increase by $2-3$ orders of magnitude.

The main factors determining the low performance, are the low occupancy of $\mathrm{CO}_{2}$ at the electrode surface due to the low solubility of $\mathrm{CO}_{2}$, and the low surface area of most electrodes. It should be noted that for simple products $(\mathrm{CO}$ and $\mathrm{HCOOH})$, occasionally high efficiency values are reported: $80-90 \%$. Intermediate values of up to $30 \%$ Faradaic efficiency were reported for methanol. For the show case of Fisher-Tropsch synthesis (FTS) products, the Faradaic efficiency was in the $1-10 \%$ range. Catalyst stability also appears to be a main issue. Carbon deposits and (over?) oxidation of the electrode surface are usually observed [20]. Clearly, catalyst development programs are needed aiming at improving activity, selectivity and stability.

\subsubsection{Reactor design and reaction conditions}

Because of the low solubility of $\mathrm{CO}_{2}$ in aqueous media a high pressure is advisable, leading to higher reaction rates. In addition, high pressures increase the CO (the first intermediate) occupancy, leading to the desired inhibition of water dissociation and, as a consequence, higher Faradaic efficiencies. If methane is the desired product, the temperature should probably be low, because of increased residence times of the intermediates at the surface. The optimum temperature for producing larger hydrocarbons has not yet been identified.

An optimal electrode design is called for. The surface area and the rate of $\mathrm{CO}_{2}$ transfer should be maximal. The benefits of fine meshes and nanowire based composites have already been demonstrated. $\mathrm{CO}_{2}$ feeding systems based on Gas Diffusion Layers work quite well [25]. Here, we enter the field of multiphase structured reactors with a wealth of design opportunities. Designs of systems have been reported in which $\mu \mathrm{m}$ sized $\mathrm{CO}_{2}$ gas bubbles are in 


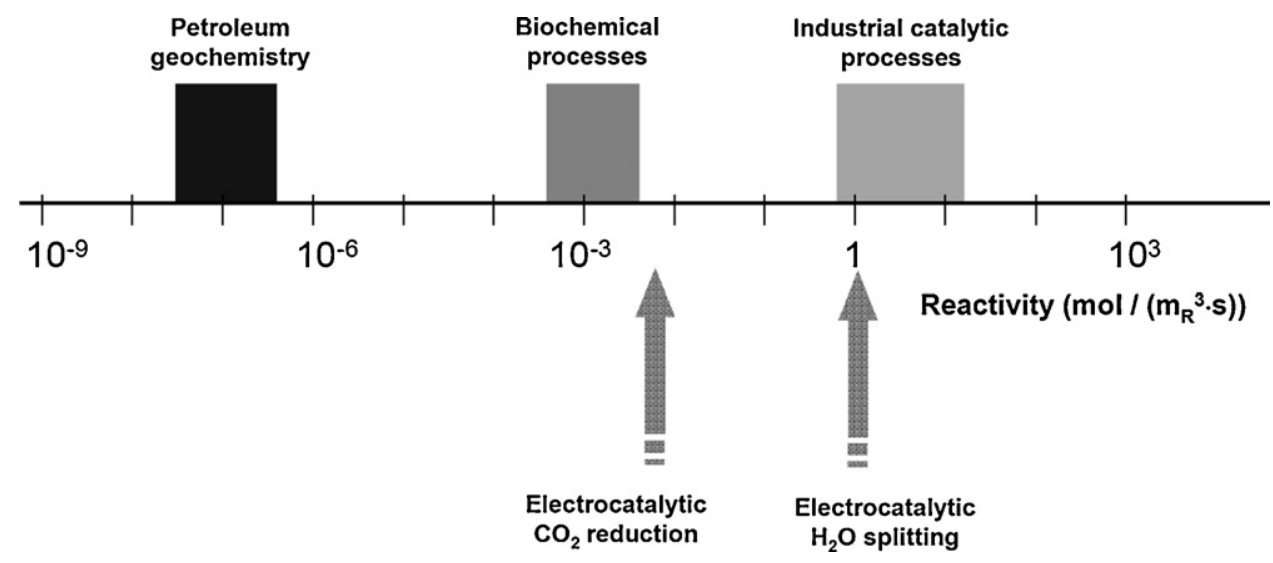

Fig. 5. Comparison space time yields of electrocatalytic processes with natural and industrial processes.

contact with the electrode surface, resulting in large mass transfer rates.

For products which have been reported with high Faradaic efficiencies $\left(\mathrm{CO}, \mathrm{CH}_{3} \mathrm{OH}, \mathrm{CH}_{4}\right)$ we anticipate that reactors can already be designed to perform at rates of commercial interest.

\subsubsection{Processes}

2.2.5.1. Conversion of $\mathrm{CO}_{2}$ into fuels by electrocatalysis. The first issue is the desired purity of the reactant. In some cases the purity is high, for instance, in the production of ammonia an essentially pure $\mathrm{CO}_{2}$ stream is produced as a by-product. Other examples are natural gas fields. In some cases they consist of roughly $50 / 50 \% \mathrm{CO}_{2} / \mathrm{CH}_{4}$. Those streams might be processed without further separation. In general, however, a separation step is required. Options are scrubbing (usually done by amines), the use of membranes, adsorption, or cryogenic separations.

The second issue is the reactor design. The basics have been discussed above. Depending on the product it might be possible to integrate reaction and product separation. If the product is not miscible with the aqueous solution, the integration becomes very attractive.

If fuels are the main products, an efficient separation is possible for gaseous and non-polar liquid phase products. The gaseous molecules, e.g., $\mathrm{CH}_{4}, \mathrm{H}_{2}$, $\mathrm{CO}$, leave the reactor from the gas phase and the larger molecules form an organic layer which is not miscible with the electrolyte phase. This leads to a very simple process design.

In cases where a polar compound is the desired product, e.g., $\mathrm{CH}_{3} \mathrm{OH}, \mathrm{C}_{2} \mathrm{H}_{5} \mathrm{OH}$, an easy separation is not possible. Options might be distillation, membrane technology or a reactive extraction by combining extraction with a chemical reaction, e.g., an etherification.

A simplified process scheme is given in Fig. 6.

2.2.5.2. Conversion of $\mathrm{CO}_{2}$ by $\mathrm{H}_{2}$ produced by electrocatalytic water splitting. The synthesis of methanol from $\mathrm{CO}_{2}$ and 'solar $\mathrm{H}_{2}$ ' can be done with conventional technology. The production of solar $\mathrm{H}_{2}$ is dealt with in the following section. High pressure is advisable because the equilibrium is more favorable at high pressure. This implies that the electrolysis cell should work at high pressure. In practice, a commercial process already exists [45]. Compared to the previous processes, reduction of $\mathrm{CO}_{2}$ by $\mathrm{H}_{2}$ by classical methanol synthesis catalysis is rather straightforward, see scheme in Fig. 7.

An advantage of this process is that the synthesis is carried out in the gas phase. This strongly simplifies the process.

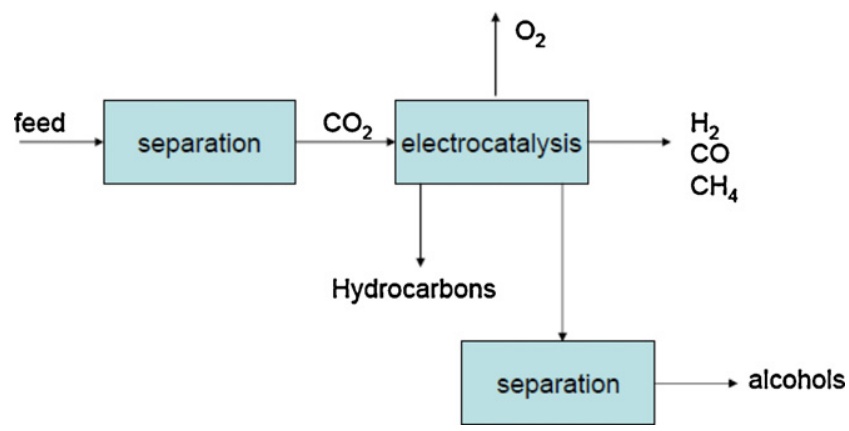

Fig. 6. Flow scheme for conversion of $\mathrm{CO}_{2}$ into fuels by electrocatalytic conversion. Hydrocarbons are produced as liquid phase.

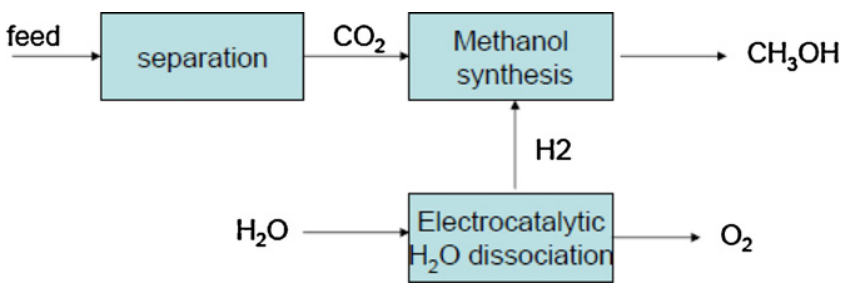

Fig. 7. Methanol synthesis according to $\mathrm{CO}_{2}+3 \mathrm{H}_{2} \rightarrow \mathrm{CH}_{3} \mathrm{OH}+\mathrm{H}_{2} \mathrm{O}$.

\subsection{Photocatalytic conversion of $\mathrm{H}_{2} \mathrm{O}$ and $\mathrm{CO}_{2}$ into fuels}

\subsubsection{Introduction}

To harvest solar energy, various options exist. As discussed in previous paragraphs, the combination of a PV solar cell, generating electrons, followed by an electrochemical process with selective electrodes to convert $\mathrm{H}_{2} \mathrm{O}$ and $\mathrm{CO}_{2}$ in fuels, is a valid option. An alternative is not to target for "fuel" directly, but target a $\mathrm{CO} / \mathrm{H}_{2}$ mixture (syn-gas) which can be converted via conventional Fischer-Tropsch catalysis to fuel, or via the methanol synthesis process to methanol. The reactions can be summarized as follows:

$\mathrm{h} v\left(+\mathrm{H}_{2} \mathrm{O} / \mathrm{CO}_{2}\right) \rightarrow \mathrm{e}\left(+\mathrm{H}_{2} \mathrm{O} / \mathrm{CO}_{2}\right) \rightarrow$ Fuel

$\mathrm{h} v\left(+\mathrm{H}_{2} \mathrm{O} / \mathrm{CO}_{2}\right) \rightarrow \mathrm{e}\left(+\mathrm{H}_{2} \mathrm{O} / \mathrm{CO}_{2}\right) \rightarrow \mathrm{CO} / \mathrm{H}_{2}+\Delta T \rightarrow$ Fuel

An interesting alternative for the PV/electrocatalysis option, is to use photocatalysts, which are able to directly convert solar energy into chemical energy. Usually, two reactions are targeted in analogy to electrocatalysis, the first being overall water splitting (OWS):

$\mathrm{h} v+2 \mathrm{H}_{2} \mathrm{O} \rightarrow 2 \mathrm{H}_{2}+\mathrm{O}_{2}$ 
and the second being the combination of $\mathrm{CO}_{2}$ activation and $\mathrm{H}_{2} \mathrm{O}$ oxidation:

$\mathrm{h} v+\mathrm{H}_{2} \mathrm{O}+\mathrm{CO}_{2} \rightarrow$ Fuel $+\mathrm{O}_{2}$

Many reports exist in the literature describing the direct conversion of solar energy into chemical energy by means of photocatalysis. In the following, we will further address the various process options.

\subsubsection{The overall water splitting reaction [5, and references therein]}

Certainly, various concepts have been described in the literature to achieve overall water splitting (OWS). These range from so-called photo-electrochemical cells (PECs) to the simple use of catalyst particles dispersed in aqueous electrolyte stirred in illuminated batch reactors. The efficiency of solar energy conversion to hydrogen ( $\mathrm{mol} \mathrm{H}_{2}$ produced per mole of solar photons exposed to the catalyst) is still low for many materials, due to fast (usually thermal) relaxation of the photo-excited state of the catalysts. Furthermore, most single component oxides active in OWS need to be activated by the UV fraction of solar radiation, which amounts to a mere 4\%. Development of improved visible light activated systems is necessary to enhance the solar hydrogen production rate, which is typically in the domain of inorganic chemists and 'band-gap engineers'. E.g., ' $N$ ' and ' $C$ ' doping have been investigated extensively to shift the band gap energy of $\mathrm{TiO}_{2}$ towards the visible region [48]. Factors that determine the applicability of other catalysts than $\mathrm{TiO}_{2}$ in photocatalytic water splitting are inertness and chemical stability (the catalyst should not change state in the process), the price, and the toxicity. An interesting design route to create a visible light sensitive water decomposition system is based on the so-called Z-scheme $[14,49]$. This is schematically illustrated in Fig. 8.

The Z-scheme operates by visible light absorption of the $\mathrm{O}_{2}$ photocatalyst, which leads to $\mathrm{O}_{2}$ production. The energy level of the photo-excited electron of this material is not high enough to induce $\mathrm{H}_{2}$ formation. It, thus, needs to recombine with the photoexcited state (the hole) of the photo-excited hydrogen evolution catalyst. The photo-excited electron of this second catalyst induces hydrogen generation. In particular, Kudo and co-workers [14,49] (Fig. 8) developed various visible-light-responsive catalyst systems for OWS based on a Z-scheme and an electron transfer by a $\mathrm{Fe}^{2+} / \mathrm{Fe}^{3+}$ redox couple. Recently self-assembly of the two catalyst particles into clusters was also found to be effective. It is evident that in both cases electron transport is suboptimal, whereas the efficiency of transfer of the photo-excited electron from the $\mathrm{O}_{2}$-photocatalyst to the $\mathrm{H}_{2}$-photocatalyst needs to be high to achieve high overall photon efficiency. The above described systems usually require 2 photons of comparable energy. One of the important challenges is to design systems in analogy to tandem solar cells, which would use different regions of the solar spectrum [51].

Usually, semiconductor performance is significantly enhanced by a noble metal promoter. The function of this noble metal promoter (e.g., Pt) on the semi-conductor surface is two-fold: it enhances the lifetime of the photo-excited state (i.e., alters physical properties) and it catalyzes the formation of $\mathrm{H}_{2}[12,52]$. Often a catalytic functionality for $\mathrm{O}_{2}$ formation is also added, such as $\mathrm{RuO}_{2}$. The disadvantage of noble metal promoters is their tendency to catalyze the back reaction of $2 \mathrm{H}_{2}+\mathrm{O}_{2} \rightarrow 2 \mathrm{H}_{2} \mathrm{O}$. This reaction can be prevented by poisoning the Pt sites with, e.g., CO, which has indeed been found to inhibit the undesired back reaction. Also Na-poisoning induced by conducting the photocatalytic water decomposition in a $\mathrm{Na}_{2} \mathrm{CO}_{3}$ solution has been demonstrated to positively affect the overall efficiency of the system in the stoichiometric photodecomposition of water $[5,13]$. Finally, the back-reaction can be prevented by creation of a protective oxide layer on the surface of the noble metal particles. This has been achieved for Rh promoted photocatalysts by deposition of $\mathrm{a}_{2} \mathrm{O}_{3}$ layer, as determined by Domen and coworkers [15]. This layer allows the hydrogen produced at the Rh surface to escape, but prevents the diffusion of oxygen to the metal surface necessary for the reaction of $\mathrm{H}_{2}$ and $\mathrm{O}_{2}$ [15].

The above described systems are all based on inorganic oxides. Besides this option, also extensive research efforts focus on the development of bio-mimetic systems, i.e., using $\mathrm{MnO}_{x}$ (water oxidation) or FeS based clusters (water reduction, generation of hydrogen) in enzyme mimics for energy transfer. A disadvantage of these organic systems is the stability. The durability will probably not allow for multiple-day operation, without the design of an adequate repair mechanism. A summary of molecular approaches can be found elsewhere [5, and references therein].

\subsubsection{Reactors}

Much of the work on the OWS reaction is either performed in an electrochemical cell configuration, or in a liquid phase batch reactor. An electrochemical cell configuration has the advantage of producing hydrogen and oxygen in separate compartments, which eliminates separation issues. On the other hand, the simplicity of a single batch reactor with a slurried catalyst is also attractive. However, it requires additional steps in separating the produced $\mathrm{H}_{2}$ from $\mathrm{O}_{2}$ and could suffer from the back-reaction of $\mathrm{H}_{2}$ and $\mathrm{O}_{2}$ to water, decreasing efficiency. The back-reaction can, however, be suppressed by smart catalyst design, as was discussed previously. Immobilization strategies for optimizing exposure of the catalysts to light, are currently under investigation, and might yield optimized solar to $\mathrm{H}_{2}$ conversion [5].

\subsubsection{Photocatalytic $\mathrm{CO}_{2}$ reduction}

While hydrogen is attractive for small (personalized) applications, certainly a liquid fuel has advantages for use in transportation applications. It has been reported that titania-based catalysts induce artificial photosynthesis, yielding single-carbon molecules in photocatalytic $\mathrm{CO}_{2}$ reduction, such as $\mathrm{CO}, \mathrm{CH}_{4}, \mathrm{CH}_{3} \mathrm{OH}$, formaldehyde and formic acid. While first studies were again conducted in the liquid phase with dissolved $\mathrm{CO}_{2}$, in more recent studies $\mathrm{CO}_{2}$ conversion was achieved in the gas phase. Productivities, in particular for crystalline semiconductors, are still extremely low. As an example, for a relatively well performing catalyst consisting of $2 \mathrm{wt} \% \mathrm{Cu}$ on $\mathrm{TiO}_{2}$, methanol yield reached $12.5 \mu \mathrm{mol} / \mathrm{g}$-cat. after $20 \mathrm{~h}$ of irradiation. To shift the absorption spectrum of crystalline $\mathrm{CO}_{2}$ photoreduction catalysts to the visible, ' $\mathrm{N}$ ' and ' $\mathrm{C}$ ' doping have been investigated. While some interesting results have been reported, productivity is still beyond the limit to design a viable process. Besides studies on crystalline $\mathrm{TiO}_{2}$ based catalysts, Ti-containing siliceous materials, such as TS-1, Ti-MCM-41, Ti-MCM-48 and Ti-SBA-15 were found to yield high methane production rates in gas phase photocatalytic $\mathrm{CO}_{2}$ reduction [5,26-29]. The production yield of highly dispersed titanium oxide catalysts (in $\mu \mathrm{mol} / \mathrm{g}-\mathrm{Ti} / \mathrm{h}$ ), was increased $10-300$ times as compared to crystalline $\mathrm{TiO}_{2}$. The activity is induced by photo-excited Ti centers generated by a so-called LMCT (Ligand to Metal Charge Transfer) transition $\left(\mathrm{Ti}^{+I V}-\mathrm{O}^{-\mathrm{II}} \rightarrow \mathrm{Ti}^{+\mathrm{III}}-\mathrm{O}^{-\mathrm{I}}\right)$ upon light absorption. Pt was found to further enhance the performance of Ti-MCM-48, also enhancing the $\mathrm{CH}_{4}$ over $\mathrm{CH}_{3} \mathrm{OH}$ selectivity [26]. Despite the numerous studies on photoreduction of $\mathrm{CO}_{2}$ over $\mathrm{TiO}_{2}$ based catalysts, relatively little is known about the surface chemistry and the mechanism of the reaction.

\subsubsection{Reactors}

Similar to the overall water splitting reaction, reactors for the photocatalytic $\mathrm{CO}_{2}$ reduction are not very well developed. Usually, flat plate reactors are used, with the catalyst immobilized on these plates and exposed to the sun. Recently, Wu et al. also tested 


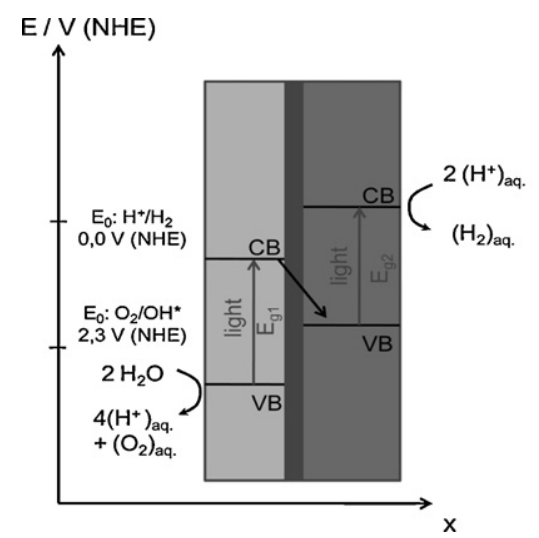

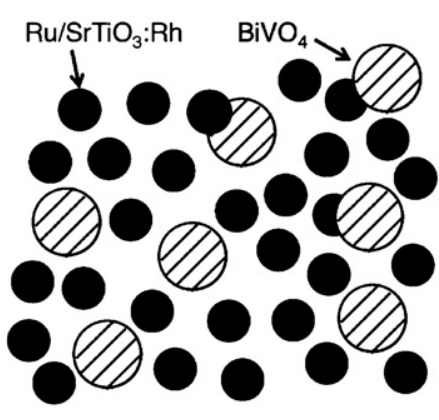

Neutral pH conditions

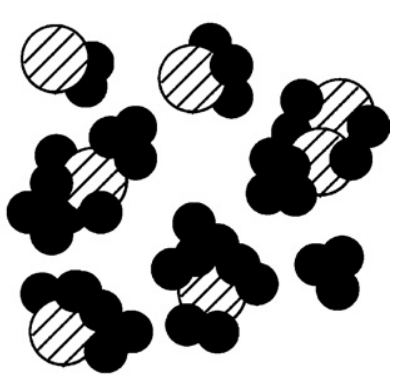

Acidic conditions

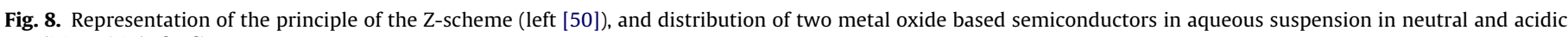
conditions (right [14]).

$\mathrm{Cu}(\mathrm{I}) / \mathrm{TiO}_{2}$ materials in an optical-fiber reactor for gas phase photocatalytic $\mathrm{CO}_{2}$ reduction. The maximum methanol yield for $1.2 \mathrm{wt} \%$ $\mathrm{Cu}$ on $\mathrm{Cu}(\mathrm{I}) / \mathrm{TiO}_{2}$ was $0.46 \mu \mathrm{mol} / \mathrm{g}$-catalyst/h under $365 \mathrm{~nm} \mathrm{UV} \mathrm{irra-}$ diation [53] The same group also used a solar collector on the roof of their building, capable of focusing sun light in optical fibers. The advantage of these optical fiber reactors is the large internal surface area, while having a reactor which is not too difficult to operate. In other words, the light collection function is separated from the catalytic converter. In these converters, elevated pressures appear beneficial for the reaction, although these are usually not applied. Investigations on the effect of reaction temperature on photocatalytic activity are also scarce. Three regimes can potentially be identified, i.e., a regime at low temperature where product desorption is limiting the overall reaction (in particular if methanol is formed this appears an issue), an intermediate regime where the reaction is kinetically controlled (with apparent activation energy being close to zero), and finally a high temperature regime where water adsorption and in particular $\mathrm{CO}_{2}$ adsorption might become limiting. Further insight on the effect of temperature on the performance of specific catalyst systems is recommended. Certainly there is also a lot to gain in photoreactor design in terms of light intensity, temperature, and pressure applied for the reaction.

\subsection{Solar thermochemical production of hydrogen}

\subsubsection{Introduction}

As early as 1960 thermal dissociation of $\mathrm{H}_{2} \mathrm{O}$ has been proposed for hydrogen production by using nuclear energy with temperatures not exceeding $1100 \mathrm{~K}$ [54]. Nowadays, solar power can be concentrated up to temperatures of $3000 \mathrm{~K}$ with heating systems that have already reached commercial maturity [55]. The concentrated energy beam is directed through an aperture into the solar receiver. Within this cavity the solar energy is absorbed to provide the reaction energy. Consequently, the equipment faces the trade-off between the maximum energy that can be absorbed by the cavity-receiver and the energy that is irradiated back through the aperture. Depending on the solar flux concentration, the subsequent optimum temperatures vary between 1100 and $1800 \mathrm{~K}$ [56]. More detailed thermodynamic evaluations of solar thermochemical processes have been reviewed elsewhere [10,54,57,58].

Very high theoretical thermal efficiencies can be reached by the direct thermolysis of water. However, the dissociation of pure water requires temperatures up to $3000 \mathrm{~K}$ (for $64 \%$ dissociation at 1 bar) [10]. Not only challenge these temperatures the materials used for the construction of the reactor, but also the separation of hydrogen and oxygen seems to pose an insurmountable barrier to realize this process [59]. An elegant route to avoid the difficulties associated with the direct splitting is the introduction of further

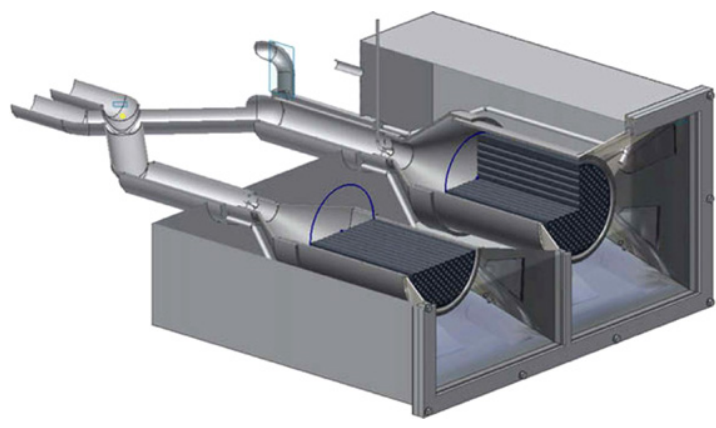

Fig. 9. Monolitic honeycomb reactor. The water splitting reaction takes place at $1073 \mathrm{~K}$, the other chamber is flushed with nitrogen for the regeneration reaction at 1473 K. After [83].

reaction steps, which reduce the temperature of the decomposition reaction and allow for the removal of hydrogen and oxygen gas in different process steps. However, further process steps come at the cost of a decreased theoretical efficiency (due to irreversibility) as well as additional reactants. Therefore, a minimum number of process steps should be targeted and reactants should be fully recycled within the system.

\subsubsection{Thermochemical cycles under consideration}

'Low-temperature' cycles, originally developed for use in combination with nuclear energy [60-63], have been extended for the application of solar energy. The adiabatic UT-3 cycle, the SulfurIodine (SI) and the Hybrigd-Iodine (HI) cycle receive much attention in the literature [64-67]. These cycles are based on a reaction scheme that incorporates more than three reactions leading to lower inherent efficiencies and high efforts for the product separation after each step. 'High-temperature' metal-oxide cycles are, usually, considered more efficient, as they comprise only two reaction steps. Usually, the first step is the endothermic solar thermal dissociation of the metal oxide into the respective metal and oxygen (reaction (10)), in which M: metal, MO: metal-oxide). Subsequently, the metal can be used to split water to hydrogen (reaction (11)). The metal-oxide produced can be recycled back to the solar process, and a second conversion (reaction (10)) can be initiated.

$$
\begin{aligned}
& \mathrm{M}_{x} \mathrm{O}_{y} \rightarrow x \mathrm{M}+y / 2 \mathrm{O}_{2} \\
& x \mathrm{M}+y \mathrm{H}_{2} \mathrm{O} \rightarrow \mathrm{M}_{x} \mathrm{O}_{x}+y \mathrm{H}_{2}
\end{aligned}
$$

These two process steps are carried out in different units of the reactor, removing the need for high temperature separation of hydrogen and oxygen. Many redox pairs have been considered in 

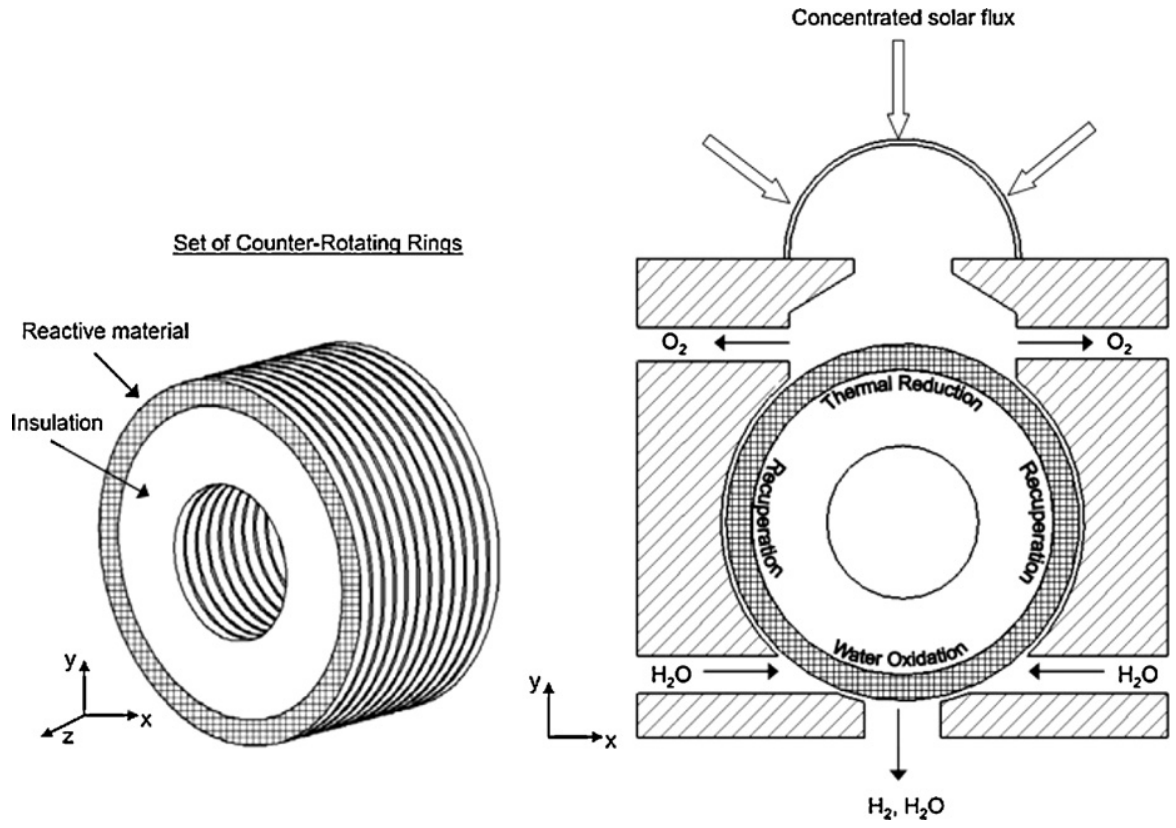

Fig. 10. Structure of the CR5 reactor [85].

the past $[10,68,69]$. It was concluded that the most feasible pairs are the $\mathrm{ZnO} / \mathrm{Zn}$ as well as $\mathrm{Fe}_{3} \mathrm{O}_{4} / \mathrm{FeO}$ redox cycles [69], having theoretical energy efficiencies of up to $82 \%$ [10] and 76\% [70], respectively, considering a complete heat recovery from the quenching procedure.

The $\mathrm{ZnO} / \mathrm{Zn}$ as well as the $\mathrm{Fe}_{3} \mathrm{O}_{4} / \mathrm{FeO}$ redox pair have already been analyzed and tested in solar reactors [65,66,69,71-74]. Both systems require the quenching of the reduction products in order to prevent re-oxidation. Although the feasibility of the iron oxide based cycle has been demonstrated [73,75], the thermodynamic requirements (operating temperature for the thermal reduction $>1800^{\circ} \mathrm{C}$ ) in combination with the material properties (melting temperatures of $\mathrm{FeO}$ around $1400^{\circ} \mathrm{C}$ [76]) prohibit the development of possible processing schemes. The use of mixed metal ferrites (with $\mathrm{Mn}, \mathrm{Ni}, \mathrm{Zn}$ ) lowers the temperature of the activation step and avoids phase transformations [77-80]. In combination with a high-temperature stable zirconia support, a material is gained that can be re-used for several cycles without elaborate processing $[53,81]$.

\subsubsection{Possible reactor configurations}

Different reactor types have been realized to meet the challenges of this process. Rob and coworkers recently presented and tested a design for a two chamber monolith reactor (compare Fig. 9), in which the redox system was coated on a honeycomb structure for advanced mass transport $[82,83]$. Two chambers are operated at different temperature levels. The water-splitting is conducted at $1073 \mathrm{~K}$, while the second chamber is regenerated by thermal reduction of oxidized ferrite at $1473 \mathrm{~K}$. This setting allows for 'quasi' continuous processing. Solar hydrogen production was accomplished for more than 50 cycles without changing the coating. The authors also designed and built a $100 \mathrm{~kW}_{\text {th }}$ solar pilot plant facility, which is currently being tested.

Up to $80 \%$ of the energy input can be lost due to the product quenching [10]. Thus, heat integration plays a key role in these types of systems. The Counter-Rotating-Ring Receiver/Reactor/Recuperator (CR5) particularly addresses this issue by transferring the concept of a Stirling cycle into their design. The reactor is based on stacks of counter-rotating disks, with ferrite coated fins along their perimeters (Fig. 10). In the high temperature part of the reactor solar energy is supplied to the fins by direct heating to power the endothermic reduction of the ferrite. Before entering the hydrolysis chamber the ferrite fin is cooled by the counter rotating neighboring rings. Experimental results proved stability for more than 30 cycles. However, after periods in the absence of irradiation, the efficiency dropped significantly, suggesting some irreversible reactions during cooling.

Slightly higher temperatures are required to run the $\mathrm{ZnO} / \mathrm{Zn}$ cycle. The hydrolysis proceeds at temperatures as low as (472-773 K). At the same time the thermal dissociation of $\mathrm{ZnO}$ requires $1872-2273 \mathrm{~K}$ [84]. At this temperature the zinc formed is in gaseous state. Quenching is, thus, not only required to avoid re-oxidation but also to separate the products. Haueter et al. presented the design of a conical rotating cavity receiver, in which the metal also serves as the solar absorber [72]. The reactants are fed into the reactor as a powder and form a thick layer on the wall due to the centripetal acceleration forces. The products are swept out by an inert gas and directly introduced to a quenching unit.

As reaction kinetics will be hindered by the heating of a flat layer, Perkins et al. present a reactor concept based on a flowing aerosol for enhanced heat and mass transfer [84]. Experiments substantiated this design with net $\mathrm{ZnO}$ conversions of $6-17 \%$, the highest conversions yet reported in literature. During quenching a fine $\mathrm{Zn}$ powder with particles in the nanometer range was formed. Funke et al. showed that fine powders can be applied to enhance the hydrolysis reaction [85].

Recent studies demonstrate that the two-step thermochemical cycles with $\mathrm{ZnO} / \mathrm{Zn}$ and Iron oxides can also be used for solar thermal carbon dioxide splitting [86-88] as well as for syngas production [75]. In principle, the same reactor configurations can be used for carbon dioxide splitting $[86,89,90]$.

\subsubsection{Challenges}

Solar thermochemical processes present high material demands not only due to the temperature levels, but also due to their transient operation as well as high heating and cooling rates (up to $10^{5} \mathrm{~K} / \mathrm{s}$ [10]. Further studies are required to ensure long term thermal shock resistance of the reactor materials. Continuous processing is difficult and efficient start-up strategies are required to rapidly reach steady state production within the short heating 
cycle. A possible route for continuous hydrogen production is the over-production of metals in the first reaction step (solar powered metal dissociation), to sustain a continuous metal hydrolysis in the second step. However, this concept comes at the cost of doubling the required solar flux.

The quenching of the reduction products usually introduces a major drop in the efficiency of the processes. The CCR5 concept demonstrates that smart integration strategies can be followed to minimize heat losses. However, new concepts (for example for the in situ removal of oxygen) are required to intensify the quenching step and advance the competitiveness of the solar production of hydrogen. The search for new metal-oxide cycles is ongoing and can provide solution for the recent challenges within the field of solar thermochemical processing. In 2008 Abanades and coworkers presented the $\mathrm{SnO}_{2} / \mathrm{SnO}$ cycle [91]. The gap between reaction temperature and the melting point of $\mathrm{SnO}$ is significantly lower as for the $\mathrm{ZnO} / \mathrm{Zn}$ cycle, lowering the dependency of the metal dissociation on the quenching rate.

In conclusion, important steps have already been taken in the development of solar thermochemical processing. During the next decades several pilot plant projects will unavoidably grant a new level of understanding of these systems.

\section{Conclusions}

Various options for solar to fuel devices have been described, comparing (i) the combination of photovoltaic (PV) devices and electrocatalysis, (ii) single unit operation by photocatalytic conversion, and (iii) solar thermal conversion. For electrocatalytic and photocatalytic technologies, dramatic improvements should be made in terms of material optimization and reactor design and operation. Both technologies could be combined with biomass conversion. Options for integrated process operation combining biomass conversion and electrocatalytic steps have been identified and have significant potential. At the same time, it is well known that combining hydrocarbon oxidation (rather than water oxidation) with photocatalytic reduction reactions (producing $\mathrm{H}_{2}$ or hydrocarbons) can significantly enhance the photonic efficiency, and might also be an interesting option in the transition to an entirely artificial photosynthesis system. Large efficiency gains are necessary to enable use of these technologies in practice. In particular, catalyst development programs for both electrocatalytic and photocatalytic technologies are needed, aiming at improving activity, selectivity and stability. For photocatalysis, one of the important additional challenges is to design Z-scheme catalytic systems in analogy to tandem solar cells, which would use different regions of the solar spectrum and allowing visible light induced catalysis. There is also a lot to gain in photoreactor design and process optimization in terms of light intensity, temperature, and pressure applied for the (gas phase) photocatalytic reactions. The authors are encouraged by the dramatic increase in research capacity that is currently (2011) established, and are confident that major steps forward to achieve the required improvements will be made. Solar thermal conversion is more mature, and requires further optimization in processing and establishment of long term thermal shock resistance of the reactor materials, as well as new metaloxide cycles lowering the dependency of the metal dissociation on the quenching rate. Also here it is to be expected that significant improvements can and will be made in the near future.

\section{References}

[1] D.J.C. MacKay, Sustainable Energy-Without the Hot Air, Cambridge, UIT, 2009.

[2] BP Statistical Review of World Energy, 2010.

[3] S. Ladanai, J. Vinterbäck, Global potential of sustainable biomass for energy, in Rapport, Institutionen energi och teknik, SLU, Uppsala, 2009.
[4] C.B. Field, Biomass energy: the scale of the potential resource, Trends in Ecology \& Evolution 23 (2008) 65-72.

[5] K. Rajeshwar, R. McConnel, S. Licht, Solar Hydrogen Generation-Toward a Renewable Energy Future, Springer Science and Business Media, 2008.

[6] G. Centi, S. Perathoner, Opportunities and prospects in the chemical recycling of carbon dioxide to fuels, Catalysis Today 148 (2009) 191-205.

[7] J. Rupprecht, B. Hankamer, J.H. Mussgnug, G. Ananyev, C. Dismukes, O. Kruse, Perspectives and advances of biological $\mathrm{H} 2$ production in microorganisms, Applied Microbiology and Biotechnology 72 (2006) 442449.

[8] G.M. Gadd, Biosorption: critical review of scientific rationale, environmental importance and significance for pollution treatment, Journal of Chemical Technology and Biotechnology 84 (2009) 13-28.

[9] B. Hankamer, F. Lehr, J. Rupprecht, J.H. Mussgnug, C. Posten, O. Kruse, Photosynthetic biomass and $\mathrm{H} 2$ production by green algae: from bioengineering to bioreactor scale-up, Physiologia Plantarum 131 (2007) 10-21.

[10] A. Steinfeld, Solar thermochemical production of hydrogen-a review, Solar Energy 78 (2005) 603-615.

[11] E. Borgarello, J. Kiwi, M. Gratzel, E. Pelizzetti, M. Visca, Visible light induced water cleavage in colloidal solutions of chromium doped titatium oxide particles, Journal of the American Chemical Society 104 (1982) 2996-3002.

[12] E. Borgarello, J. Kiwi, E. Pelizzetti, M. Visca, M. Gratzel, Photochemical cleavage of water by photocatalysis, Nature 289 (1981) 158-160.

[13] A. Kudo, Y. Miseki, Heterogeneous photocatalyst materials for water splitting, Chemical Society Reviews 38 (2009) 253-278.

[14] Y. Sasaki, H. Nemoto, K. Saito, A. Kudo, Solar water splitting using powdered photocatalysts driven by Z-schematic interparticle electron transfer without an electron mediator, Journal of Physical Chemistry C 113 (2009) $17536-17542$.

[15] K. Maeda, A.K. Xiong, T. Yoshinaga, T. Ikeda, N. Sakamoto, T. Hisatomi, M. Takashima, D.L. Lu, M. Kanehara, T. Setoyama, T. Teranishi, K. Domen, Photocatalytic overall water splitting promoted by two different cocatalysts for hydrogen and oxygen evolution under visible light, Angewandte ChemieInternational Edition 49 (2010) 4096-4099.

[16] N. Sakamoto, H. Ohtsuka, T. Ikeda, K. Maeda, D.L. Lu, M. Kanehara, K. Teramura, T. Teranishi, K. Domen, Highly dispersed noble-metal/chromia (core/shell) nanoparticles as efficient hydrogen evolution promoters for photocatalytic overall water splitting under visible light, Nanoscale 1 (2009) 106-109.

[17] C.C. Yang, Y.H. Yu, B. van der Linden, J.C.S. Wu, G. Mul, Artificial photosynthesis over crystalline $\mathrm{TiO}_{2}$-based catalysts: fact or fiction? Journal of the American Chemical Society 132 (2010) 8398-8406.

[18] G. Centi, S. Perathoner, Towards solar fuels from water and $\mathrm{CO}_{2}$, Chemsuschem 3 (2010) 195-208.

[19] H. Shibata, J.A. Moulijn, G. Mul, Enabling electrocatalytic Fischer-Tropsch synthesis from carbon dioxide over copper-based electrodes, Catalysis Letters 123 (2008) 186-192.

[20] Y. Hori, H. Konishi, T. Futamura, A. Murata, O. Koga, H. Sakurai, K. Oguma, "Deactivation of copper electrode" in electrochemical reduction of $\mathrm{CO}_{2}$, Electrochimica Acta 50 (2005) 5354-5369.

[21] Y. Hori, A. Murata, R. Takahashi, Formation of hydrocarbons in the electrochemical reduction of carbon-dioxide at a copper electrode in aqueous solution, Journal of the Chemical Society-Faraday Transactions I 85 (1989) 2309-2326.

[22] W.Y. Lin, H.X. Han, H. Frei, $\mathrm{CO}_{2}$ splitting by $\mathrm{H}_{2} \mathrm{O}$ to $\mathrm{CO}$ and $\mathrm{O} 2$ under UV light in TiMCM-41 silicate sieve, Journal of Physical Chemistry B 108 (2004) 18269-18273.

[23] W.Y. Lin, H. Frei, Photochemical $\mathrm{CO}_{2}$ splitting by metal-to-metal chargetransfer excitation in mesoporous $\mathrm{ZrCu}(\mathrm{I})-\mathrm{MCM}-41$ silicate sieve, Journal of the American Chemical Society 127 (2005) 1610-1611.

[24] D.G. Nocera, Personalized energy: the home as a solar power station and solar gas station, ChemSusChem 2 (2009) 387-390.

[25] G. Centi, S. Perathoner, G. Wine, M. Gangeri, Electrocatalytic conversion of $\mathrm{CO}_{2}$ to long carbon-chain hydrocarbons, Green Chemistry 9 (2007) $671-678$.

[26] M. Anpo, H. Yamashita, K. Ikeue, Y. Fujii, S.G. Zhang, Y. Ichihashi, D.R. Park, Y. Suzuki, K. Koyano, T. Tatsumi, Photocatalytic reduction of $\mathrm{CO}_{2}$ with $\mathrm{H}_{2} \mathrm{O}$ on Ti-MCM-41 and Ti-MCM-48 mesoporous zeolite catalysts, Catalysis Today 44 (1998) 327-332.

[27] H. Yamashita, Y. Fujii, Y. Ichihashi, S.G. Zhang, K. Ikeue, D.R. Park, K. Koyano, T. Tatsumi, M. Anpo, Selective formation of $\mathrm{CH}_{3} \mathrm{OH}$ in the photocatalytic reduction of $\mathrm{CO}_{2}$ with $\mathrm{H}_{2} \mathrm{O}$ on titanium oxides highly dispersed within zeolites and mesoporous molecular sieves, Catalysis Today 45 (1998) 221-227.

[28] S.G. Zhang, Y. Fujii, K. Yamashita, K. Koyano, T. Tatsumi, M. Anpo, Photocatalytic reduction of $\mathrm{CO}_{2}$ with $\mathrm{H}_{2} \mathrm{O}$ on Ti-MCM-41 and Ti-MCM-48 mesoporous zeolites at $328 \mathrm{~K}$, Chemistry Letters (1997) 659-660.

[29] M. Anpo, H. Yamashita, Y. Ichihashi, Y. Fujii, M. Honda, Photocatalytic reduction of $\mathrm{CO}_{2}$ with $\mathrm{H}_{2} \mathrm{O}$ on titanium oxides anchored within micropores of zeolites: Effects of the structure of the active sites and the addition of Pt, Journal of Physical Chemistry B 101 (1997) 2632-2636.

[30] F.D. Mercader, M.J. Groeneveld, S.R.A. Kersten, N.W.J. Way, C.J. Schaverien, J.A. Hogendoorn, Production of advanced biofuels: Co-processing of upgraded pyrolysis oil in standard refinery units, Applied Catalysis B: Environmental 96 (2010) 57-66.

[31] S. Kabashi, S. Bekteshi, S. Ahmetaj, G. Kabashi, D. Najdovski, A. Zidansek, I. Slaus, Effects of Kosovo's energy use scenarios and associated gas emissions 
on its climate change and sustainable development, Applied Energy 88 (2011) 473-478.

[32] V. Knapp, D. Pevec, M. Matijevic, The potential of fission nuclear power in resolving global climate change under the constraints of nuclear fuel resources and once-through fuel cycles, Energy Policy 38 (2010) 6793-6803.

[33] R.C. Ewing, W. Runde, T.E. Albrecht-Schmitt, Environmental impact of the nuclear fuel cycle: fate of actinides, Mrs Bulletin 35 (2010) 859-866.

[34] C.J. Lawn, Technologies for tomorrow's electric power generation, Proceedings of the Institution of Mechanical Engineers Part C: Journal of Mechanical Engineering Science 223 (2009) 2717-2742.

[35] D.F. Montoro, in EPIA presentation at the SUNRISE FINAL FORUM, 2009.

[36] S. Ito, H. Miura, S. Uchida, M. Takata, K. Sumioka, P. Liska, P. Comte, P. Pechy, M. Graetzel, High-conversion-efficiency organic dye-sensitized solar cells with a novel indoline dye, Chemical Communications (2008) 5194-5196.

[37] M. Zukalova, J. Prochazka, A. Zukal, J.H. Yum, L. Kavan, M. Graetzel, Organized mesoporous $\mathrm{TiO}_{2}$ films stabilized by phosphorus: application for dye-sensitized solar cells, Journal of the Electrochemical Society 157 (2010) H99-H103.

[38] B.P. Karsten, R.K.M. Bouwer, J.C. Hummelen, R.M. Williams, R.A.J. Janssen, Charge separation and recombination in small band gap oligomer-fullerene triads, Journal of Physical Chemistry B 114 (2010) 14149-14156.

[39] A.A. Bakulin, D. Martyanov, D.Y. Paraschuk, P.H.M. van Loosdrecht, M.S. Pshenichnikov, Charge-transfer complexes of conjugated polymers as intermediates in charge photogeneration for organic photovoltaics, Chemical Physics Letters 482 (2009) 99-104.

[40] N.S. Lewis, D.G. Nocera, Powering the planet: chemical challenges in solar energy utilization, Proceedings of the National Academy of Sciences of the United States of America 103 (2006) 15729-15735.

[41] Z.L. Zhan, L. Zhao, Electrochemical reduction of $\mathrm{CO}_{2}$ in solid oxide electrolysis cells, Journal of Power Sources 195 (2010) 7250-7254.

[42] D.T. Whipple, E.C. Finke, P.J.A. Kenis, Microfluidic reactor for the electrochemical reduction of carbon dioxide: the effect of $\mathrm{pH}$, Electrochemical and Solid State Letters 13 (2010) D109-D111.

[43] A.A. Peterson, F. Abild-Pedersen, F. Studt, J. Rossmeisl, J.K. Norskov, How copper catalyzes the electroreduction of carbon dioxide into hydrocarbon fuels, Energy \& Environmental Science 3 (2010) 1311-1315.

[44] S. Ohya, S. Kaneco, H. Katsumata, T. Suzuki, K. Ohta, Electrochemical reduction of $\mathrm{CO}_{2}$ in methanol with aid of $\mathrm{CuO}$ and $\mathrm{Cu}_{2} \mathrm{O}$, Catalysis Today 148 (2009) 329-334.

[45] H. Wendt, H. Vogt, G. Kreysa, D.M. Kolb, G.E. Engelmann, J.G. Ziegler, H. Goldacker, K. Juttner, U. Galla, H. Schmieder, E. Steckhan, Electrochemistry. Ullmann's Encyclopedia of Industrial Chemistry, Wiley, 2009.

[46] L.E. Barrosse-Antle, R.G. Compton, Reduction of carbon dioxide in 1butyl-3-methylimidazolium acetate, Chemical Communications (2009) 3744-3746.

[47] M. Schwartz, M.E. Vercauteren, A.F. Sammells, FISCHER-TROPSCH electrochemical $\mathrm{CO}_{2}$ reduction to fuels and chemicals, Journal of the Electrochemical Society 141 (1994) 3119-3127.

[48] O. Carp, C.L. Huisman, A. Reller, Photoinduced reactivity of titanium dioxide, Progress in Solid State Chemistry 32 (2004) 33-177.

[49] H. Kato, M. Hori, R. Konta, Y. Shimodaira, A. Kudo, Construction of Zscheme type heterogeneous photocatalysis systems for water splitting into $\mathrm{H} 2$ and $\mathrm{O} 2$ under visible light irradiation, Chemistry Letters 33 (2004) 1348-1349.

[50] B. Neumann, P. Bogdanoff, $\mathrm{H}$. Tributsch, $\mathrm{TiO}_{2}$-protected photoelectrochemical tandem $\mathrm{Cu}(\mathrm{In}, \mathrm{Ga}) \mathrm{Se} 2$ thin film membrane for light-induced water splitting and hydrogen evolution, Journal of Physical Chemistry C 113 (2009) 20980-20989.

[51] T.A. Moore, Workshop 'Towards Bio Solar Cells', Leiden, The Netherlands, 2010.

[52] J. Kiwi, E. Borgarello, E. Pelizzetti, M. Visca, M. Gratzel, Cyclic water celavage by visible light. Drastic improvement of yield of $\mathrm{H} 2$ and $\mathrm{O} 2$ with bifunctional redux catalysts, Angewandte Chemie-International Edition 19 (1980) 646-648.

[53] T. Kodama, Y. Kondoh, R. Yamamoto, H. Andou, N. Satou, Thermochemical hydrogen production by a redox system of $\mathrm{ZrO}_{2}$-supported $\mathrm{Co}$ (II)-ferrite, Solar Energy 78 (2005) 623-631.

[54] J.E. Funk, R.M. Reinstrom, Energy requirements in production of hydrogen from water, Industrial \& Engineering Chemistry Process Design and Development 5 (1966) 336-342.

[55] C. Richter, J. Blanco, P. Heller, M. Mehos, A. Meier, R. Meyer, W. Weiss, Solar power and chemical energy systems, in Solar Paces Annual Report, Solar Paces, 2008.

[56] A. Steinfeld, M. Schubnell, Optimum aperture size and operating temperature of a solar cavity receiver, Solar Energy 50 (1993) 19-25.

[57] E.A. Fletcher, Solarthermal processing: a review, Journal of Solar Energy Engineering-Transactions of the ASME 123 (2001) 63-74.

[58] D.R. Okeefe, J.H. Norman, D.G. Williamson, Catalysis research in thermochemical water-splitting processes, Catalysis Reviews-Science and Engineering 22 (1980) 325-369.

[59] E. Wilhelm, M. Fowler, A Technical and economic review of solar hydrogen production technologies, Bulletin of Science, Technology \& Society 26 (2006) 278-287.

[60] C.E. Bamberger, Hydrogen production from water by thermochemical cycles-1977 update, Cryogenics 18 (1978) 170-183.

[61] G.E. Beghi, A decade of research on thermochemical hydrogen at the joint research center, ISPRA, International Journal of Hydrogen Energy 11 (1986) 761-771.
[62] J.E. Funk, Thermochemical hydrogen production: past and present, International Journal of Hydrogen Energy 26 (2001) 185-190.

[63] S. Yalcin, A review of nuclear hydrogen production, International Journal of Hydrogen Energy 14 (1989) 551-561.

[64] M. Sakurai, N. Miyake, A. Tsutsumi, K. Yoshida, Analysis of a reaction mechanism in the UT-3 thermochemical hydrogen production cycle, International Journal of Hydrogen Energy 21 (1996) 871-875.

[65] M. Sakurai, E. Bilgen, A. Tsutsumi, K. Yoshida, Solar UT-3 thermochemical cycle for hydrogen production, Solar Energy 57 (1996) 51-58.

[66] E. Bilgen, M. Ducarroir, M. Foex, F. Sibieude, F. Trombe, Use of solar energy for direct and 2-step water decomposition cycles, International Journal of Hydrogen Energy 2 (1977) 251-257.

[67] A. Le Duigou, J.M. Borgard, B. Larousse, D. Doizi, R. Allen, B.C. Ewan, G.H. Priestman, R. Elder, R. Devonshire, V. Ramos, G. Cerri, C. Salvini, A. Giovannelli, G. De Maria, C. Corgnale, S. Brutti, M. Roeb, A. Noglik, P.M. Rietbrock, S. Mohr, L. De Oliveira, N. Monnerie, M. Schmitz, C. Sattler, A.O. Martinez, D.D. Manzano, J.C. Rojas, S. Dechelotte, O. Baudouin, HYTHEC: an EC funded search for a long term massive hydrogen production route using solar and nuclear technologies, International Journal of Hydrogen Energy 32 (2007) 1516-1529.

[68] F. Fresno, R. Fernandez-Saavedra, M.B. Gomez-Mancebo, A. Vidal, M. Sanchez, M.I. Rucandio, A.J. Quejido, M. Romero, Solar hydrogen production by two-step thermochemical cycles: evaluation of the activity of commercial ferrites, International Journal of Hydrogen Energy 34 (2009) 2918-2924.

[69] A. Steinfeld, P. Kuhn, A. Reller, R. Palumbo, J. Murray, Y. Tamaura, Solarprocessed metals as clean energy carriers and water-splitters, International Journal of Hydrogen Energy 23 (1998) 767-774.

[70] J.E. Miller, M.D. Allendorf, R.B. Diver, L.R. Evans, N.P. Siegel, J.N. Stuecker, Meta oxide composites and structures for ultra-high temperature solar thermochemical cycles, Journal of Materials Science 43 (2008) 4714-4728.

[71] R. Palumbo, J. Lede, O. Boutin, E.E. Ricart, A. Steinfeld, S. Moller, A Weidenkaff, E.A. Fletcher, J. Bielicki, The production of $\mathrm{Zn}$ from $\mathrm{ZnO}$ in a high-temperature solar decomposition quench process-I. The scientific framework for the process, Chemical Engineering Science 53 (1998) 2503-2517.

[72] P. Haueter, S. Moeller, R. Palumbo, A. Steinfeld, The production of zinc by thermal dissociation of zinc oxide-solar chemical reactor design, Solar Energy 67 (1999) 161-167.

[73] A. Steinfeld, S. Sanders, R. Palumbo, Design aspects of solar thermochemical engineering-a case study: two-step water-splitting cycle using the $\mathrm{Fe}_{3} \mathrm{O}_{4} / \mathrm{FeO}$ redox system, Solar Energy 65 (1999) 43-53.

[74] T. Nakamura, Hydrogen profuction from water utilizing solar heat at high temperatures, Solar Energy 19 (1977) 467-475.

[75] A. Stamatiou, P.G. Loutzenhiser, A. Steinfeld, Solar syngas production via $\mathrm{H}_{2} \mathrm{O} / \mathrm{CO}_{2}$-splitting thermochemical cycles with $\mathrm{Zn} / \mathrm{ZnO}$ and $\mathrm{FeO} / \mathrm{Fe}_{3} \mathrm{O}_{4}$ redox reactions, Chemistry of Materials 22 (2010) 851-859.

[76] T. Kodama, N. Gokon, R. Yamamoto, Thermochemical two-step water splitting by $\mathrm{ZrO}_{2}$-supported $\mathrm{Ni}_{x} \mathrm{Fe}_{3}-x \mathrm{O}_{4}$ for solar hydrogen production, Solar Energy 82 (2008) 73-79.

[77] Y. Tamaura, A. Steinfeld, P. Kuhn, K. Ehrensberger, Production of solater hydrogen by a novel, 2-step, water-splitting thermochemical cycle, Energy 20 (1995) 325-330.

[78] K. Ehrensberger, A. Frei, P. Kuhn, H.R. Oswald, P. Hug, Comparitive experimental investigations of the water-splitting reaction with iron oxide and iron-manganese oxides, Solid State Ionics 78 (1995) 151-160.

[79] K. Ehrensberger, P. Kuhn, V. Shklover, H.R. Oswald, Temporary phase segregation processes during the oxidation of ( $\mathrm{Fe} 0.7 \mathrm{Mn0.3})(0.99) \mathrm{O}$ in $\mathrm{N}_{2}-\mathrm{H}_{2} \mathrm{O}$ atmosphere, Solid State Ionics 90 (1996) 75-81.

[80] Y.Tamaura, M. Kojima, T. Sano, Y. Ueda, N. Hasegawa, M. Tsuji, Thermodynamic evaluation of water splitting by a cation-excessive ( $\mathrm{Ni}, \mathrm{Mn}$ ) ferrite, International Journal of Hydrogen Energy 23 (1998) 1185-1191.

[81] T. Kodama, High-temperature solar chemistry for converting solar heat to chemical fuels, Progress in Energy and Combustion Science 29 (2003) 567-597.

[82] M. Roeb, M. Neises, J.P. Sack, P. Rietbrock, N. Monnerie, J. Dersch, M. Schmitz, C. Sattler, Operational strategy of a two-step thermochemical process for solar hydrogen production, International Journal of Hydrogen Energy 34 (2009) 4537-4545.

[83] C. Agrafiotis, M. Roeb, A.G. Konstandopoulos, L. Nalbandian, V.T. Zaspalis, C. Sattler, P. Stobbe, A.M. Steele, Solar water splitting for hydrogen production with monolithic reactors, Solar Energy 79 (2005) 409-421.

[84] C. Perkins, P.R. Lichty, A.W. Weimer, Thermal ZnO dissociation in a rapid aerosol reactor as part of a solar hydrogen production cycle, International Journal of Hydrogen Energy 33 (2008) 499-510.

[85] H.H. Funke, H. Diaz, X.H. Liang, C.S. Carney, A.W. Weimer, P. Li, Hydrogen generation by hydrolysis of zinc powder aerosol, International Journal of Hydrogen Energy 33 (2008) 1127-1134.

[86] P.G. Loutzenhiser, M.E. Galvez, I. Hischier, A. Graf, A. Steinfeld, $\mathrm{CO}_{2}$ splitting in an aerosol flow reactor via the two-step $\mathrm{Zn} / \mathrm{ZnO}$ solar thermochemical cycle, Chemical Engineering Science 65 (2010) 1855-1864.

[87] M.E. Galvez, P.G. Loutzenhiser, I. Hischier, A. Steinfeld, $\mathrm{CO}_{2}$ splitting via two-step solar thermochemical cycles with $\mathrm{Zn} / \mathrm{ZnO}$ and $\mathrm{FeO} / \mathrm{Fe}_{3} \mathrm{O}_{4}$ redox reactions: thermodynamic analysis, Energy \& Fuels 22 (2008) 35443550.

[88] P.G. Loutzenhiser, M.E. Galvez, I. Hischier, A. Stamatiou, A. Frei, A. Steinfeld, $\mathrm{CO}_{2}$ splitting via two-step solar thermochemical cycles with $\mathrm{Zn} / \mathrm{ZnO}$ 
and $\mathrm{FeO} / \mathrm{Fe}_{3} \mathrm{O}_{4}$ redox reactions II: kinetic analysis, Energy \& Fuels 23 (2009) 2832-2839.

[89] L.O. Schunk, A. Steinfeld, Kinetics of the thermal dissociation of $\mathrm{ZnO}$ exposed to concentrated solar irradiation using a solar-driven thermogravimeter in the $1800-2100 \mathrm{~K}$ range, AIChE Journal 55 (2009) 1497-1504.
[90] L.O. Schunk, P. Haeberling, S. Wepf, D. Wuillemin, A. Meier, A. Steinfeld, A receiver-reactor for the solar thermal dissociation of zinc oxide, Journal of Solar Energy Engineering-Transactions of the ASME 130 (2008) 6.

[91] S. Abanades, P. Charvin, F. Lemont, G. Flamant, Novel two-step $\mathrm{SnO}_{2} / \mathrm{SnO}$ watersplitting cycle for solar thermochemical production of hydrogen, International Journal of Hydrogen Energy 33 (2008) 6021-6030. 